PSICOLOGIA, SAÚDE \& DOENÇAS, 2020, 21(3), 782-795

ISSN - 2182-8407

Sociedade Portuguesa de Psicologia da Saúde - SPPS - www.sp-ps.pt

DOI: http://dx.doi.org/10.15309/20psd210320

\title{
ALTERED STATES OF CONSCIOUSNESS, ABSORPTION, AND SEXUAL RESPONSIVENESS
}

\author{
Jacopo Ellero $^{1} \&$ Rui Costa ${ }^{2}$ \\ ${ }^{1}$ ISPA - Instituto Universitário, Lisbon, Portugal, jacumelar@gmail.com \\ ${ }^{2}$ William James Center for Research, ISPA - Instituto Universitário, Lisbon, Portugal, rcosta@ispa.pt
}

\begin{abstract}
Sexual intercourse alters normal waking consciousness. Altered states of consciousness (ASC) refer to marked deviations from usual waking consciousness, and include alterations in the sense of self, attention, thought processes, time awareness and sensory perception. Sex can induce ASC, as indicated by states of attentional absorption in bodily sensations concomitant with loss of time awareness. The present study aimed at testing if, during sexual relations, higher sexual responsiveness relates to higher intensity of dimensions of ASC that can occur in other contexts, such as meditation or use of psychoactive substances. The personality trait of absorption appears to reflect individual differences in the proclivity to experience ASC; thus, a second aim was to examine if trait absorption relates to intensity of ASC during sex. The international sample consisted of 448 participants (303 women, 145 men). Sex-induced ASC were measured with four sub-scales of The Altered States of Consciousness Rating Scale (OAV): Experience of Unity, Spiritual Experience, Blissful State and Insightfulness. Trait absorption was measured by the Modified Tellegen Absorption Scale (MODTAS). Sexual responsiveness during the last intercourse was assessed by the sum of measures of arousal, desire, and satisfaction, as well as by questions on the occurrence of orgasm from different sexual activities. Trait absorption and sexual responsiveness predicted independently all dimensions of ASC among women and men. In women, vaginal orgasm (during vaginal intercourse without concomitant clitoral masturbation) was an additional independent predictor of ASC. Male orgasm related to ASC, but not independently from other aspects of sexual responsiveness.
\end{abstract}

Keywords: Altered states of consciousness, sexuality, absorption, orgasm, spirituality.

\section{ESTADOS ALTERADOS DE CONSCIÊNCIA, ABSORÇÃO E RESPONSIVIDADE SEXUAL}

RESUMO: As relações sexuais alteram a consciência vígil usual. Estados alterados de consciência (EAC) referem-se a desvios marcados da consciência vígil usual. Investigação confirma que EAC podem ocorrer no sexo em termos de estados de absorção atencional nas sensações corporais concomitantes à perda de consciência do tempo. O presente estudo testou se, durante as relações sexuais, maior responsividade

ISPA - Instituto Universitário, Rua do Jardim do Tabaco 34, 1100-304 Lisbon, Portugal. Telephone: 21 881 1700. Email: rcosta@ispa.pt 
sexual está relacionada com maior intensidade em dimensões de EAC que podem ocorrer com desencadeantes não sexuais, como meditação ou substâncias psicoactivas. Adicionalmente, o traço de personalidade "absorção" parece reflectir diferenças individuas na propensão para EAC. Assim, um segundo objetivo foi examinar se a absorção traço se relaciona com a intensidade de EAC durante o sexo. A amostra internacional contou com 448 participantes (303 mulheres, 145 homens). Os EAC foram medidos com quatro sub-escalas da Altered States of Consciousness Rating Scale (OAV): Experiência de Unidade, Experiência Espiritual, Estado de Beatitude e Momentos de Insight. A absorção-traço foi medida pela Modified Tellegen Absorption Scale (MODTAS). A responsividade durante a última relação sexual foi medida através da soma de medidas de excitação, desejo, satisfação, assim como com questões sobre a ocorrência do orgasmo através de diversas actividades sexuais. Absorção-traço e responsividade sexual foram preditores independentes da intensidade de todas as dimensões dos EAC em mulheres e homens. Nas mulheres, o orgasmo vaginal feminino (durante o coito vaginal sem masturbação clitoriana concomitante) foi um preditor independente adicional dos EAC. O orgasmo masculino relacionou-se com os EAC, mas não independentemente dos outros aspectos da responsividade sexual.

Palavras-Chave: Estados alterados de consciência, sexualidade, absorção, orgasmo, espiritualidade

Recebido em 02 de outubro de 2020/ Aceite em 02 de novembro de 2020

Sexual intercourse requires one's attention to be focused; the target of attention usually encompasses one's interoceptive and proprioceptive sensations, as well as partner's body and behavioural feedbacks. Especially in a highly involving intercourse, these attentional processes can elicit a state of "absorption". Absorbed states are mental states caused by the intense attention towards imagination and sensory experiences, which lead to changes in the perception of self, space, and time (Dal Cin et al., 2016; Tellegen \& Atkinson, 1974). In this sense, absorption in a high degree can lead to altered states of consciousness (ASC), that is, "a marked deviation in the subjective experience or psychological functioning of a normal individual from her/his usual waking consciousness." This implies "an unusual experience of oneself and one's surroundings. Time and space as fundamental categories of human experience are changed" (Dittrich, 1998, p. 80). Clinical and theoretical speculation in sexology and psychotherapy mentions ASC as a possible outcome of a sexual intercourse (Maslow, 1959; Mosher, 1980; Metz \& McCarthy, 2007; Passie et al., 2003; Swartz, 1994). The current investigation aims to expand the limited empirical evidence regarding the occurrence of ASC in sex.

\section{Absorption}

Some people are more prone to experiencing absorbed states than others; therefore, absorption exists along a personality trait continuum (Tellegen \& Attkinson, 1974). Trait absorption correlates with hypnotic susceptibility. Fascination is one possible synonym for "absorbed state" (Tellegen \& Atkinson, 1974). These states do typically occur in quiet, effortless conditions, devoid of significant activity, planning, and decision making (Tellegen, 1981).

States of absorption occur in non-ordinary experiences reported in meditation, expanded awareness, peak experiences (Maslow, 1968), mysticism, esthetic experience, regression in the service of the ego, altered states of consciousness, and effects of drugs (Tellegen \& Atkinson, 1974). 
Swartz (1994) built his cognitive theory of human sexual response on the premise that all sexual activity is based on an attentional focus necessary for sexual arousal. Such alteration in one's attention facilitates the access to absorbed states, and vice versa: absorption in erotic stimuli, imagination, or both, can elicit arousal. During sexual activity the phenomenological field would encompass heightened focus in bodily sensations, reduction in attention towards the surroundings, and alteration in the perception of time (timelessness). According to Swartz, high levels of absorption in the sexual experience would enhance sexual arousal and pleasure for men, but they are not essential for male sexual response, whilst, for most women, high levels of absorption would be essential for high sexual arousal and orgasm.

Costa et al. (2016a) tested these hypotheses empirically with self-report questionnaires about the experience in the last sexual relation and found confirmation for them. For both men and women, greater body awareness correlated strongly with greater desire, arousal, and satisfaction, but for women more strongly so. Occurrence of orgasm correlated strongly with body awareness in women, but only moderately in men. In women, loss of time awareness correlated strongly with desire, arousal, orgasm, and satisfaction, but in men, only satisfaction correlated moderately with loss of time awareness. The correlations between sexual responses and loss of awareness of surrounding space were somewhat stronger for men, but modest.

While state absorption is important for sexual responsiveness, it is not clear to what extent trait absorption relates to sexual functioning. Some studies suggest that it might have a role, at least in some dimensions of sexual function. Sexual arousability was associated with the ability to engage in mental imagery (Harris et al., 1980), which is a characteristic of trait of absorption. A personality trait that overlaps conceptually with absorption is "Creative Self-Forgetfulness", which was associated with higher sexual desire in women and men (Costa et al., 2016b; Costa et al., 2018). Consistency of female orgasm during sexual intercourse was related to hypnotic susceptibility (Bridges et al., 1985), which is a consistent correlate of trait absorption.

Mindfulness meditation training is practiced by focusing attention and awareness on the present moment, and it was shown to improve sexual desire, arousal and satisfaction in women (Brotto \& Basson, 2014). Mindfulness meditation may increase trait absorption (Bowden et al., 2012), but it is presently unclear if putative increases in propensity for absorption caused by mindfulness are a mechanism that helps in improving sexual function.

\section{Altered states of consciousness (ASC)}

Although everyday life absorbed states are not necessarily ASC, the personality trait of absorption might facilitate the occurrence of ASC. In a factor analysis of the TAS (Jamieson, 2005), one factor emerged, which was named "Altered States of Consciousness," and includes the following items: "Sometimes I feel as if my mind could envelop the whole world." "I think I really know what some people mean when they talk about mystical experiences" "I sometimes step outside myself and experience an entirely different state of being". "Sometimes I experience things as if they were doubly real." However, only a deep absorbed state can be considered an ASC.

\section{Objectives}

Other aspects of ASC are commonly reported as feelings of unity with the environment, blissfulness, profound peace and love, spiritual experiences and insightfulness. The present study aims at testing if higher sexual responsiveness is related to these aspects of ASC. Because trait absorption is theoretically linked with ASC, a second aim is to examine if trait absorption is related to these aspects of ASC. 


\section{METHODS}

\section{Participants and procedure}

Four hundred forty-eight participants - 145 males and 303 females (see Table 1) - replied to the online questionnaire developed on the platform GoogleForms, after giving informed consent. The introduction to the questionnaire explained the context of the research, the voluntary basis of participation, the anonymity and confidentiality of the answers, and linked to an e-mail address for eventual questions. Participants were reminded that they could leave answers blank in case they did not feel comfortable in answering honestly. The study had the approval of local the Ethics Committee of ISPA.

Participants were contacted on the basis of virtual snowball sampling on the principle of convenience in social networks and via e-mail. To broaden the reach of the investigation the identical set of questions was presented in two languages: Portuguese and English. 81 participants replied to the Portuguese version ( 25 males, 56 females), and 367 to the English version (120 males, 247 females). There was a single link to the questionnaire, which would then display different instruments depending on the gender of the participant. Specific questions on sexual activity in terms of a heterosexual cisgender relationship would not be displayed in case the participant had not engaged in such during the previous month.

Several participants with a substantial amount of missing values in the values of interest were excluded from the final sample. Participants were excluded from the univariate correlational analyses if in treatment with psychiatric medication and/or under the influence of recreational psychoactive substances (PASs) during the last sexual intercourse (alcohol included; see Costa et al., 2016a; Ogden et al., 2011), but they were included in the multiple regressions predicting ASC. Consumption of nicotine in isolation was not a criterion for exclusion.

Ninety-eight participants reported consumption of PASs during the last intercourse (29 males, 69 females), 1 male participant used antipsychotic medication, and 27 reported the use of antidepressants ( 5 males and 14 females in isolation; 1 male and 7 females in conjunction with use of PASs during the last intercourse). This accounts for the exclusion of 118 participants ( 35 males, 83 female) from the univariate correlational analyses.

The most reported PASs consumed in isolation were alcohol ( 9 males, 21 females) and cannabis ( 5 males, 21 females). Poly-consumption mixing the two substances was also reported ( 7 males, 7 females). Tobacco was also used alongside alcohol ( 3 males, 10 females). The use of other PASs was sporadic and included: GHB (1 male), MDMA (1 male, 1 female), alcohol and MDMA (1 female), cannabis and MDMA (1 male, 1 female), alcohol and GHB (1 female), alcohol and cannabis ( 1 male, 1 female), alcohol, nicotine, and methamphetamine ( 1 male), nicotine, MDMA, cocaine and morphine (1 female), cannabis, cocaine, MDMA, opiates and hallucinogens (not better specified) (1 male).

\section{Materials}

Sociodemographic information. Questions regarded gender, age, profession, academic qualification, sexual partners, health problems, and use of medications and PASs.

Absorption. The MODTAS - Modified Tellegen Absorption Scale (Jamieson, 2005) was used to measure the trait of Absorption by self-report. It comprises 34 items in Likert-type scale from 1 to 5 ("Totally disagree" to "Totally agree"). Examples are: "Sometimes I feel as if my mind could envelop the whole world.", "If I wish I can imagine (or daydream) some things so vividly that they 
hold my attention as a good movie or story does.", "It is sometimes possible for me to be completely immersed in nature or in art and to feel as if my whole state of consciousness has somehow been temporarily altered".

Sexual satisfaction, desire and arousal during last sexual intercourse were measured with a scale from 1 ("Not at all") to 5 ("Extremely") (Costa et al., 2016a). For the linear regression analysis the items were summed in a single variable.

Orgasm occurrence during last sexual relation was assessed with dichotomous items (Yes, No). For women, there were questions regarding orgasm attained through a) penile-vaginal intercourse without concomitant clitoral masturbation, b) penile-vaginal intercourse with concomitant clitoral masturbation, c) partnered non-coital sex" (partnered practices of masturbation, oral sex and anal sex). For men, there were questions regarding orgasm attained through a) penile-vaginal intercourse", b) partnered non-coital sex". A composite measure of orgasm was computed indicating the occurrence of orgasm regardless of triggering activity $(0=$ no orgasm; $1=$ reported orgasm).

Altered states of consciousness (ASC) during last sexual relation were measured with the OAV Altered States of Consciousness Rating Scale (Studerus et al., 2010). The items are derived from the more extended version in German language of the APZ (Abnormal Mental States) Questionnaire (Dittricht, 1998), translated into other languages and "applied internationally in approximately 70 experimental studies" (Studerus et al., 2010, p.1) for measuring the alteration of consciousness elicited by different kinds of sensory and pharmacological stimulation.

The introduction to the questionnaire in the current study stated: "Follows a set of statements that describe states that can be triggered by substance use, hypnosis, meditation, or some life events. Sometimes they also occur during sexual activity. Indicate to what extent you felt that these states were occurring during your last sexual intercourse or shortly after, compared to your usual day-today awareness (in non-sexual contexts). Indicate the change you felt with a number between 1 and 100." The 42 items were chosen from the larger version of OAV along eleven lower-order factors on the basis of the psychometric evaluation conducted by the authors. This version of OAV was validated by pooling data from 43 experimental studies, which confirmed an adequate internal consistency: Cronbach's $\alpha>0.8(\mathrm{n}=591)$ (Studerus et al., 2010).

For the statistical analysis of the current investigation, only four factors were included. The literature (Maslow, 1959; Metz \& McCarthy, 2007; Mosher, 1980; Swartz, 1994) identifies phenomenological experiences in the alteration of consciousness during sex pertaining especially (though not exclusively) to the four dimensions of: Blissful State, Experience of Unity, Spiritual Experience, and Insightfulness. The significant strength of these 4 factors of the OAV was confirmed in this study (see Table 2). The items describing each factor are as follows:

Blissful State: "I enjoyed boundless pleasure." "I experienced a profound peace in myself." "I experienced an all-encompassing love."

Experience of Unity: "Everything seemed to unify into an oneness." "It seemed to me that my environment and I were one." "I experienced a touch of eternity." "Conflicts and contradictions seemed to dissolve." "I experienced past, present and future as a oneness".

Spiritual Experience: "I had the feeling of being connected to a superior power." "I experienced a kind of awe." "My experience had religious aspects."

Insightfulness: "I felt very profound." "I gained clarity in connections that puzzled me before." "I had very original thoughts."

\section{RESULTS}

Table 1 presents the sociodemographic characteristics of the participants. The majority of the participants were European (89.8\% of the female subgroup, $72.9 \%$ of the male subgroup). 
Table 1. Sociodemographics.

\begin{tabular}{|c|c|c|}
\hline & Women $(N=278)$ & $\operatorname{Men}(N=127)$ \\
\hline & $N(\%)$ or average $\left(S D^{*}\right)$ & $N(\%)$ or average $\left(S D^{*}\right)$ \\
\hline Age & $27.90(9.23)$ & $29.20(8.97)$ \\
\hline \multicolumn{3}{|l|}{ Academic qualifications } \\
\hline Less than grade 12 & $13(4.7 \%)$ & $11(8.7 \%)$ \\
\hline 12th grade & $40(14.4 \%)$ & $20(15.7 \%)$ \\
\hline University student & $41(14.7 \%)$ & $12(9.4 \%)$ \\
\hline Bachelor's Degree & $105(37.8 \%)$ & $39(30.7 \%)$ \\
\hline Master's Degree & $56(20.1 \%)$ & $30(23.6 \%)$ \\
\hline Higher Qualifications & $12(4.3 \%)$ & $7(5.5 \%)$ \\
\hline \multicolumn{3}{|l|}{ Profession } \\
\hline Student & $136(48.9 \%)$ & $56(44.1 \%)$ \\
\hline Worker & $125(45.0 \%)$ & $66(52.0 \%)$ \\
\hline Student worker & $2(0.7 \%)$ & $2(1.6 \%)$ \\
\hline Unemployed & $6(2.2 \%)$ & $2(1.6 \%)$ \\
\hline Retired & $7(2.5 \%)$ & 0 \\
\hline \multicolumn{3}{|l|}{ Civil Status } \\
\hline Single & $234(84.2 \%)$ & $105(82.7 \%)$ \\
\hline Married & $14(5.0 \%)$ & $8(6.3 \%)$ \\
\hline Divorced & $5(1.8 \%)$ & $5(3.9 \%)$ \\
\hline Widow or widower & $1(0.4 \%)$ & 0 \\
\hline With a regular sex partner & $168(60.4 \%)$ & $71(55.9 \%)$ \\
\hline \multicolumn{3}{|l|}{ Nationality } \\
\hline Portuguese & $57(20.5 \%)$ & $22(17.3 \%)$ \\
\hline Italian & $119(42.8 \%)$ & $56(44.1 \%)$ \\
\hline European (Other) & $73(26.3 \%)$ & $33(26.0 \%)$ \\
\hline Northern America & $12(4.3 \%)$ & $4(3.1 \%)$ \\
\hline Latin America & $5(1.8 \%)$ & $6(5.0 \%)$ \\
\hline Australia & $1(0.4 \%)$ & 0 \\
\hline Asia & $2(0.7 \%)$ & $3(2.4 \%)$ \\
\hline Africa & $2(0.7 \%)$ & 0 \\
\hline \multicolumn{3}{|l|}{ Exclusion criteria } \\
\hline Use of psychiatric medication** & $20(7.2 \%)$ & $7(5.5 \%)$ \\
\hline Use of PASs during last sexual intercourse** & $67(24.1 \%)$ & $26(20.5 \%)$ \\
\hline
\end{tabular}




\section{ALTERED STATES OF CONSCIOUSNESS THROUGH SEX}

* $S D=$ Standard Deviation; PASs $=$ Psychoactive substances ; ** Exclusion criteria from the univariate analyses. Due to overlap, a total of 112 participants (32 males, 80 females) were excluded.

Table 2. Descriptive statistics of ASC $(N=293)$

\begin{tabular}{lccccc}
\hline & Mean & $S D^{*}$ & Median & Min & Max \\
\hline Experience of Unity & 37.16 & 25.231 & 36 & 1 & 100 \\
Spiritual Experience & 22.68 & 22.189 & 17 & 1 & 97 \\
Blissful State & 49.47 & 31.197 & 53 & 1 & 100 \\
Insightfulness & 29.76 & 26.759 & 25 & 1 & 100 \\
\hline
\end{tabular}

*Standard Deviation

Tables 3 and 4 present the correlations dimensions of ASC elicited by sex (Experience of Unity, Spiritual Experience, Blissful State, and Insightfulness), sexual responsiveness, occurrence of orgasm and absorption.

In the female subgroup, absorption, satisfaction, desire, and arousal correlated with ASC. In the male subgroup, correlations were similar, but with some differences: arousal and satisfaction did not correlate significantly with Spiritual Experience nor did absorption correlate with Blissful State.

In the female subgroup, only orgasm by vaginal intercourse without clitoral masturbation correlated with all the dimensions of ASC. Orgasm by partnered noncoital sex correlated with Blissful State. Occurrence of orgasm (any trigger) correlated with Experience of Unity and Blissful State. In the male subgroup, orgasm by vaginal intercourse did not correlate with ASC. Orgasm by partnered noncoital sex correlated with all dimensions of ASC with the exception of Insightfulness. The occurrence of orgasm (any trigger) correlated with Experience of Unity, Insightfulness, and Blissful State, but not with Spiritual Experience.

Table 3. Correlations between sexual involvement, absorption and ASC in the female subgroup

\begin{tabular}{|c|c|c|c|c|}
\hline$N=198$ & $\begin{array}{l}\text { Experience } \\
\text { of Unity }\end{array}$ & $\begin{array}{l}\text { Spiritual } \\
\text { Experience }\end{array}$ & $\begin{array}{c}\text { Blissful } \\
\text { State }\end{array}$ & Insightfulness \\
\hline Absorption & $.41 * * *$ & $.33 * * *$ & $.28 * * *$ & $.39 * * *$ \\
\hline Satisfaction & $.33 * * *$ & $.29 * * *$ & $.55 * * *$ & $.33 * * *$ \\
\hline Desire & $.40 * * *$ & $.34 * * *$ & $.53 * * *$ & $.35 * * *$ \\
\hline Arousal & $.36 * * *$ & $.27 * * *$ & $.47 * * *$ & $.27 * * *$ \\
\hline $\begin{array}{l}\text { Orgasm by vaginal intercourse without clitoral } \\
\text { masturbation }\end{array}$ & $.29 * * *$ & $.23 * *$ & $.37 * * *$ & $.25 * *$ \\
\hline $\begin{array}{l}\text { Orgasm by vaginal intercourse with clitoral } \\
\text { masturbation }\end{array}$ & .01 & .02 & .00 & .01 \\
\hline Orgasm by partnered non-coital sex & .08 & .06 & $.16 *$ & .09 \\
\hline Orgasm (any) & $.16 *$ & .12 & $.26 * *$ & .12 \\
\hline
\end{tabular}

${ }^{*} p<.05: * * p<.01 ; * * *<.001$

Table 4. Correlations between sexual involvement, absorption and ASC in the male subgroup

\begin{tabular}{ll|l|l|l}
\hline$N=95$ & Experience & Spiritual & Blissful & Insightfulness \\
\hline
\end{tabular}




\begin{tabular}{lccccc}
\hline & of Unity & Experience & State & \\
\hline Absorption & $\mathbf{. 3 4} * *$ & $\mathbf{. 4 2} * *$ & .09 & $\mathbf{. 2 9} * *$ \\
Satisfaction & $\mathbf{. 3 3 * *}$ & .19 & $\mathbf{. 4 3} * * *$ & $\mathbf{. 3 5 * *}$ \\
Desire & $\mathbf{. 2 9 * *}$ & $\mathbf{. 3 2} * *$ & $\mathbf{. 5 1} * * *$ & $\mathbf{. 4 2 * * *}$ \\
Arousal & $\mathbf{. 2 3 *}$ & .20 & $\mathbf{. 4 5} * * *$ & $\mathbf{. 3 4 * *}$ \\
Orgasm by vaginal intercourse & -.01 & -.03 & .09 & .10 \\
Orgasm by partnered noncoital sex & $\mathbf{. 2 6 *}$ & $\mathbf{. 2 4} *$ & $\mathbf{. 2 2 *}$ & .17 \\
Orgasm (any) & $\mathbf{. 2 5 *}$ & .16 & $\mathbf{. 3 6 * * *}$ & $\mathbf{. 2 3 *}$ \\
\hline
\end{tabular}

${ }^{*} p<.05 ; * * p<.01 ; * * *<.001$

Table 5 and 6 present the correlations between sexual responsiveness (satisfaction, desire, arousal) with occurrence of orgasm (differentiated on the basis of triggering activity) in female (Table 5) and male (Table 6) subgroups.

Table 5. Correlations between sexual responsiveness and occurrence of orgasm in the female subgroup

\begin{tabular}{lccc}
\hline$N=198$ & Desire & Arousal & Satisfaction \\
\hline Orgasm by vaginal intercourse without clitoral masturbation & $\mathbf{. 2 7 * * *}$ & $\mathbf{. 2 2 * *}$ & $\mathbf{. 3 3 * * *}$ \\
Orgasm by vaginal intercourse with clitoral masturbation & $\mathbf{. . 1 8 *}$ & $\mathbf{- . 1 8 *}$ & -.07 \\
Orgasm by partnered non-coital sex & .13 & .12 & $\mathbf{. 2 2 * *}$ \\
Orgasm (any trigger) & $\mathbf{. 2 6 * * *}$ & $\mathbf{. 2 1 * *}$ & $\mathbf{. 4 1 * * *}$ \\
\hline
\end{tabular}

${ }^{*} p<.05 ; * * p<.01 ; * * * p<.001$

Table 6. Correlations between Sexual responsiveness and occurrence of orgasm in the male subgroup

\begin{tabular}{lccc}
\hline$N=95$ & Desire & Arousal & Satisfaction \\
\hline Orgasm by vaginal intercourse & $\mathbf{. 2 2}$ & .09 & .13 \\
Orgasm by partnered noncoital sex & .04 & .04 & .10 \\
Orgasm (any trigger) & $\mathbf{. 3 0 * *}$ & $\mathbf{. 3 3} * *$ & $\mathbf{. 3 2 * *}$ \\
\hline
\end{tabular}

$* p<.05 ; * * p<.01$

Tables 7 and 8 show multiple linear regressions with predictors of ASC. In women, absorption and sexual responsiveness explained changes in the four dimensions of consciousness. Occurrence of orgasm by vaginal intercourse without clitoral masturbation additionally and independently predicted ASC in the four dimensions, but more weakly than absorption and sexual responsiveness.

In the male subgroup (Table 8), absorption and sexual responsiveness explained changes in the four dimensions of consciousness.

Table 7. Linear regression in the female subgroup $(N=278)$. 


\begin{tabular}{|c|c|c|c|c|}
\hline & $\begin{array}{l}\text { Experience of } \\
\text { Unity }\end{array}$ & $\begin{array}{l}\text { Spiritual } \\
\text { Experience }\end{array}$ & Blissful State & Insightfulness \\
\hline Age & $.08(.125)$ & $.05(.355)$ & $.10(.036)$ & $.03(.570)$ \\
\hline Absorption & $.40(>.001)$ & $.37(>.001)$ & $.25(>.001)$ & $.41(>.001)$ \\
\hline Sexual Responsiveness & $.34(>.001)$ & $.31(>.001)$ & $.49(>.001)$ & $.26(>.001)$ \\
\hline $\begin{array}{l}\text { Orgasm by vaginal intercourse without } \\
\text { clitoral masturbation }\end{array}$ & $.13(.020)$ & $.11(.044)$ & $.12(.041)$ & $.12(.041)$ \\
\hline Orgasm by partnered noncoital sex & $.05(.393)$ & $.05(.417)$ & $.06(.266)$ & $.06(.266)$ \\
\hline Use of tobacco & $-.03(.600)$ & $.02(.731)$ & $-.01(.893)$ & $-.01(.893)$ \\
\hline Use of PASs & $-.02(.704)$ & $.05(.389)$ & $-.04(.499)$ & $-.04(.499)$ \\
\hline Use of antidepressants & $.001(.988)$ & $-.04(.476)$ & $-.01(.850)$ & $-.01(.850)$ \\
\hline
\end{tabular}

Table 8. Linear regression in the male subgroup $(N=127)$.

\begin{tabular}{lcccc}
\hline & Experience of Unity & Spiritual Experience & Blissful State & Insightfulness \\
\hline Age & $.09(.077)$ & $-.04(.609)$ & $\mathbf{. 1 2}(\mathbf{. 0 1 8})$ & $.07(.440)$ \\
Absorption & $\mathbf{. 4 2}(>\mathbf{. 0 0 1})$ & $\mathbf{. 4 5}(>\mathbf{. 0 0 1})$ & $\mathbf{. 2 7}(>\mathbf{. 0 0 1})$ & $\mathbf{. 2 8}(>\mathbf{. 0 0 1})$ \\
Sexual responsiveness & $\mathbf{. 3 7}(>\mathbf{. 0 0 1})$ & $\mathbf{. 1 9}(\mathbf{. 0 3 6})$ & $\mathbf{. 5 3}(\mathbf{. 0 0 1})$ & $\mathbf{. 3 2}(\mathbf{. 0 0 1})$ \\
Orgasm (any) & $.06(.320)$ & $.01(.907)$ & $.06(.238)$ & $-.003(.973)$ \\
Use of tobacco & $-.03(.528)$ & $-.07(.386)$ & $.02(.689)$ & $.030(.727)$ \\
Use of PASs & $-.02(.688)$ & $.12(.135)$ & $-.04(.406)$ & $.09(.285)$ \\
Use of antidepressants & $.000(.994)$ & $-.06(.437)$ & $-.02(.734)$ & $-.10(.265)$ \\
\hline
\end{tabular}

To elucidate why ASC did not relate significantly with male orgasm and female noncoital orgasm, we run partial correlations between these variables controlling for sexual responsiveness. After controlling for sexual responsiveness, female noncoital orgasm became uncorrelated with Blissful State $(r=.05, p=.410)$, and male orgasm became uncorrelated with Blissful State $(r=.13$, $p=.149)$, Experience of Unity $(r=.07, p=.446)$, Insightfulness $(r=.01, p=.934)$ and Spiritual Experience $(r=.01, p=.930)$.

\section{DISCUSSION}

The results confirm that, during sex, it is possible to experience alterations of consciousness in comparison to daily life awareness - without mind-altering substances - as measured in the OAV (Studerus et al., 2010).

The multiple linear regressions (Tables 7 and 8) show that sex-induced ASC are independently explained by higher sexual responsiveness and by the personality propensity for absorbed states. This means that very high levels of desire, arousal and satisfaction have the potential to induce nonordinary states of consciousness. In addition, for people more prone to absorbed states and thereby to ASC in daily life, sex has a strong potential to induce exceptional states of consciousness even if the sexual responsiveness is not very high. The combination of higher sexual responsiveness and www.sp-ps.pt 
personality propensity for absorption would make the occurrence of ASC more likely. As Maslow noted, "Some fortunate people can almost always have a peak-experience in sex" (Maslow, 1962, p. 13). Some gender differences were observed. The effects were more consistent and stronger in the female subgroup for all the four dimensions of ASC, which seems to confirm that ASC are somehow more connected to female sexual response (Costa et al., 2016a; Swartz, 1984).

In women, coital orgasm without clitoral masturbation (sometimes termed vaginal orgasm) correlated with all the dimensions of ASC, but orgasms during other sexual behaviors did not (except weakly for Blissful State). Besides, vaginal orgasm correlated with ASC independently of sexual responsiveness and absorption. Vaginal orgasm is a controversial subject with many women reporting that have difficulties attaining orgasm by penile-vaginal intercourse alone (Jannini et al., 2012). More recent research has been suggesting that there are physiological differences between orgasm by vaginal penetration and orgasm by stimulating the clitoral gland (Brody, 2017; Jannini et al., 2012; Jannini et al., 2019). Future research is need to clarify if vaginal orgasm is more likely to happen during exceptional states of consciousness, and this makes it more infrequent. According to a study almost all women (95\%) reports that clitoral stimulation contributes to their orgasms, while only $65 \%$ report that vaginal stimulation contributes to orgasm, and even less $(35 \%)$ report that cervical stimulation contributes to orgasm (Jannini et al., 2019). Interestingly, orgasms elicited by cervical stimulation were described in more abstract manners that are reminiscent of ASC, such as provoking "showers of stars" or "images of universal spaciousness" (Jannini et al., 2019) In the study by Costa and colleagues (2016a), occurrence of vaginal orgasm was related to greater changes in the perception of time than noncoital orgasms or coital orgasms with clitoral masturbation.

Unlike vaginal orgasm, neither male orgasm nor female noncoital orgasm predicted ASC in the multiple regression, suggesting that they did not correlate with ASC beyond sexual responsiveness of which they are a culmination. This was corroborated by partial correlations.

The dimension of Blissful state presented the highest scores in the study (an average score of 49). The increases in blissfulness are likely due to the fact that in most circumstances sex is pleasurable and may cause pleasurable states that can last for days (Meltzer et al., 2017); thus, it should be of little surprise that sex-induced non-ordinary states of consciousness are normally characterized by blissfulness.

The Experience of Unity can be interpreted as deep connection with the partner (Swartz, 1994) or as universal union (Mosher, 1980). Particularly after the orgasm, the experience of unity is described through "sensations of merging", that is "loosening and dissolution of personal boundaries" (Swartz, 1994), altered sense of time (e.g., "timelessness"), and body image change (dissolution of boundaries) (Mosher, 1980). Phenomena of alteration of time perception during intercourse were previously confirmed empirically: lessened sense of time correlated with increased sexual responsiveness (with stronger effects for women than for men). In the same study, orgasm was related to lesser time awareness in women, but not in men (Costa et al., 2016a).

The dimension of Insightfulness was commonly increased by sexual activity. It seems that sex can sometimes promote insights. Orgasm can loose mental associations (Hartmann et al., 2005), and loosening of mental association appears to be important for insights (Karimi et al., 2007). Thus, very intense sexual experiences might have the potential to cause exceptional moments of insight.

Spiritual Experience was the dimensions of ASC that changed less with sexual activity. Ascribing sacred qualities to sex (e.g., holiness, blessed) was positively associated with positive affective reactions to sex, frequency of sex, and number of sexual partners among university students (Murray-Swank et al., 2005). Ascribing sacred qualities to sex might be related to items such as "I experienced a kind of awe" and "My experience had religious aspects."

Spiritual experiences during sex are thought to arise spontaneously, but nevertheless their likelihood appears to be increased by the predisposition of the individual and the couple (Mosher, 1980). For both sexes, trait absorption predicted Spiritual Experience in the multiple regressions. 


\section{ALTERED STATES OF CONSCIOUSNESS THROUGH SEX}

Trait absorption has been consistently related to propensity for spiritual and mystical experiences (Lifschitz et al., 2019). Users of substances such as cannabis sometimes report a spiritual purpose for consumption (Solymosi \& Kofalvi, 2017; Yeterian et al., 2018). However, in the multiple regressions, use of PAS did not influence the associations of Spiritual Experience with orgasm, sexual responsiveness and absorption.

The association between spirituality and sexual practices (Burris et al., 2009; Murray-Swank et al., 2005) highlights the relevance of future investigations pertaining spiritual disposition and alteration along the Spiritual Experience sub-scale.

Novel approaches to sex therapy were developed expecting spiritual experiences as possible outcomes (Metz \& McCarthy; 2007). Mindfulness is applied in sex therapy, especially for female sexual dysfunctions (Mize, 2015). Mindfulness is a system of meditation based on nonjudgmental attentional focus on the perceptions of the present moment (Brotto \& Basson, 2004; Brotto et al., 2008), so that it could elicit states of absorption - meditation is one possible trigger (Tellegen \& Atkinson, 1974). Mindfulness practice was found to increase trait absorption (Bowden et al., 2012), but it is presently unclear if this increase in trait absorption helps in improving sexual function.

The ASC observed in the present study describe mostly the experiences of European young adults. The virtual snowballing on the basis of convenience is one limitation of the study; geocultural differences might be expected to reflect upon ASC in sex in future replications. The quality of a well-established sexual partnership should reflect upon the involvement in the intercourse. It is unclear if deeper alterations occur in populations older and/or in positive sexual partnerships of long duration. In the present study, there was a small percentage of married participants $(5.0 \%$ of females and $6.3 \%$ of males). These are questions for future studies.

Another methodological limitation is the focus on the last sexual relation. Future research should aim at establishing the frequency and consistency of ASC for longer periods. In the present study, ASC correlated positively with higher sexual satisfaction: identifying facilitating factors for the experience of sex-related ASC might benefit sex therapy.

The present study examined the psychological alterations triggered by sex in terms of naturally occurring ASC. Such alterations were explained independently by trait absorption and involvement in the sexual relation, that is, higher sexual responsiveness and orgasm. However, gender differences were observed: in women there were more consistent associations of trait absorption and sexual responsiveness with all the dimensions of ASC. The altered consciousness most commonly induced by sex appeared to be characterized mainly by an intense bliss and the experience of unity, "beyond the boundaries of the self". Insights and spiritual experiences may also occur.

\section{REFERENCES}

Bridges, C. F., Critelli, J. W., \& Loos, V. E. (1985). Hypnotic susceptibility, inhibitory control, and orgasmic consistency. Archives of Sexual Behavior, 14, 373-376. https://doi.org/10.1007/BF01550852

Brody, S. (2017). Evaluation of female orgasmic disorder. In W. IsHak (Ed.) Textbook of Clinical Sexual Medicine (pp. 203-218). https://doi.org/10.1007/978-3-319-52539-6_14

Bowden, D., Gaudry, C., An, S. C., \& Gruzelier, J. (2012). A comparative randomised controlled trial of the effects of brain wave vibration training, iyengar yoga, and mindfulness on mood, well-being, and salivary cortisol. Evidence-Based Complementary and Alternative Medicine, 2012, Article 234713. https://doi.org/10.1155/2012/234713 
Brotto, L. A., \& Basson, R. (2014). Group mindfulness-based therapy significantly improves sexual desire in women. Behavioral Research and Therapy, 57, 43-54. https://doi.org/10.1007/BF01550852

Brotto, L. A., Krychman, M., \& Jacobson, P. (2008). Eastern Approaches for Enhancing Women's Sexuality: Mindfulness, Acupuncture, and Yoga (CME). Journal of Sexual Medicine, 5(12), 2741-2748. https://doi.org/10.1111/j.1743-6109.2008.01071.x

Burris, J. L., Smith, G. T., \& Carlson, C. R. (2009). Relations among religiousness, spirituality, and sexual practices. Journal of Sex Research, 46, 282-289. https://doi.org/10.1080/ 00224490802684582.

Costa, R. M., Oliveira, T. F., Pestana, J., \& Costa, D. (2016b). Self-transcendence is related to higher female sexual desire. Personality and Individual Differences, 96, 191-197. https://doi.org/ 10.1016/j.paid.2016.02.078

Costa, R. M., Pestana, J., Costa, D., \& Wittmann, M. (2016a). Altered states of consciousness are related to higher sexual responsiveness. Consciousness and Cognition, 42, 135-141. https://doi.org/10.1016/j.concog.2016.03.013

Csikszentmihalyi, M., \& Csikszentmihalyi, I. S. (1988). Optimal experience: psychological studies of flow in consciousness. Cambridge University Press. https://doi.org/10.1017/CBO9780511621956

Dal Cin, S., Hall, M.P., \& Lane, D.S. (2016) Absorption. In Zeigler-Hill V., \& Shackelford T. (eds) Encyclopedia of Personality and Individual Differences. Springer, Cham. https://doi.org/10.1007/978-3-319-28099-8_1117-1

Dittrich, A. (1998). The standardized psychometric assessment of altered states of consciousness (ASCs) in humans. Pharmacopsychiatry, 31, 80-84. doi: 10.1055/s- 2007-979351.

Harris, R., Yulis, S., \& Lacoste, D. (1980). Relationships among sexual arousability, imagery ability, and introversion-extraversion. Journal of Sex Research, 16, 72-86. https://doi.org/10.1080/00224498009551063

Jamieson G. A. (2005). The Modified Tellegen Absorption Scale: a clearer window on the structure and meaning of absorption. Australian Journal of Clinical and Experimental Hypnosis, 33(2), 119-139.

Jannini, E., Rubio-Casillas, A., Whipple, B., Buisson, O., Komisaruk, B., \& Brody, S. (2012). Female orgasm(s): one, two, several. Journal of Sexual Medicine, 9, 956-965. https://doi.org/10.1111/j.1743-6109.2012.02694.x.

Jannini, E., Wise, N., Frangos, E., \& Komisaruk, B. R. (2019). Peripheral and central neural bases of orgasm. In I. Goldstein, A. H., Clayton, A. T. Goldstein, N. N. Kim, S. A. Kingsberg (Eds), Textbook of Female Sexual Function and Dysfunction, pp. 179-185. Wiley-Blackwell. https://doi.org/10.1002/9781119266136.ch13

Karimi, Z., Windmann, S., Güntürkün, \& Abraham, A. (2007). Insight problem solving in individuals with high versus low schizotypy. Journal of Research in Personality, 41, 473-480. https://doi.org/10.1016/j.jrp.2006.03.008

Maslow, A. H. (1962). Lessons from the peak-experiences. Journal of Humanistic Psychology, 2, 19-18. https://doi.org/10.1177/002216786200200102

Lifschitz, M., van Elk, M., \& Luhrmann, M. (2019). Absorption and spiritual experience: A review of evidence and potential mechanisms. Consciousness and Cognition, 73, 102760. https://doi.org/10.1016/j.concog.2019.05.008

Maslow, A. H. (1968). Toward a psychology of being (2nd ed.). Van Nostrand. https://doi.org/10.1037/10793-000

Maslow, A. H. (1959). Cognition of Being in the Peak Experiences. The Journal of Genetic Psychology, 94(1), 43-66. https://doi.org/10.1080/00221325.1959.10532434 


\section{ALTERED STATES OF CONSCIOUSNESS THROUGH SEX}

Meltzer, A. L., Makhanova, A. L., Hicks, L. L., French, J. E., McNulty, J. K., \& Bradbury, T. N. (2017). Quantifying the sexual afterglow: the lingering benefits of sex and their implications for

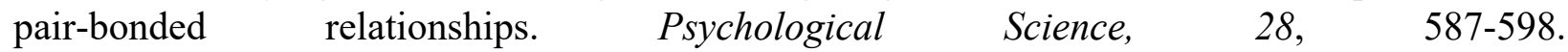
https://doi.org/10.1177/09567976176913

Metz, M. E., \& McCarthy, B. W. (2007). The «Good-Enough Sex» model for couple sexual satisfaction. Sexual and Relationship Therapy, 22(3), 351-362. https://doi.org/10.1080/14681990601013492

Mize, S. J. S. (2015). A Review of Mindfulness-Based Sex Therapy Interventions for Sexual Desire and Arousal Difficulties: From Research to Practice. Current Sexual Health Reports, 7(2), 8997. https://doi.org/10.1007/s11930-015-0048-8

Mosher, D. L. (1980). Three dimensions of depth of involvement in human sexual response. Journal of Sex Research, 16, 1-42.

Murray-Swank, N. A., Pargament, K. I., \& Mahoney, A. (2005). At the crossroads of sexuality and spirituality: The sanctification of sex by college students. The International Journal for the Psychology of Religion, 15, 199-219. https://doi.org/10.1207/s15327582ijpr1503_2

Ogden, R. S., Wearden, J. H., Gallagher, D. T., \& Montgomery, C. (2011). The effect of alcohol administration on human timing: A comparison of prospective timing, retrospective timing and passage of time judgements. Acta Psychologica, 138, 254-262. https://doi.org/10.1016/j.actpsy.2011.07.002

Passie, T., Hartmann, U., Schneider, U., \& Emrich, H. M. (2003). On the function of groaning and hyperventilation during sexual intercourse: intensification of sexual experience by altering brain metabolism through hypocapnia. Medical Hypotheses, 60(5), 660-663. https://doi.org/10.1016/s0306-9877(03)00010-0

Passie, T., Hartmann, U., Schneider, U., \& Emrich, H. M, \& Krüger, T. H. C. (2005). Ecstasy (MDMA) mimics the post-orgasmic state: impairment of sexual drive and function during acute MDMA effects may be due to increased prolactin secretion. Medical Hypotheses, 65, 899-903. https://doi.org/10.1016/j.mehy.2004.11.044

Qualls, P. J. \& Sheehan, P. W. (1981). Imagery encouragement, absorption capacity and relaxation during electromyograph biofeedback. Journal of Personality and Social Psychology, 41, 370379. https://doi.org/10.1037/0022-3514.41.2.370

Solymosi, K., \& Kofalvi, A. (2017). Cannabis: A treasure trove or pandora's box? Mini-Reviews in Medicinal Chemistry, 17(13). https://doi.org/10.2174/1389557516666161004162133

Studerus E., Gamma A., \& Vollenweider, F. X. (2010). Psychometric evaluation of the altered states of consciousness rating scale (OAV). PLoS ONE, 5(8), e12412. https://doi.org/10.1371/journal.pone.0012412

Swartz, L. H. (1994). Absorbed states play different roles in female and male sexual response: Hypotheses for testing. Journal of Sex \& Marital Therapy, 20, 244-253. https://doi.org/10.1080/00926239408403434

Tellegen, A. (1981). Practicing the two disciplines for relaxation and enlightenment: Comment on "Role of the feedback signal in electromyograph biofeedback: The relevance of attention" by Qualls and Sheehan. Journal of Experimental Psychology: General, 110(2), 217-226. https://doi.org/10.1037/0096-3445.110.2.217

Tellegen, A., \& Atkinson, G. (1974). Openness to absorbing and self-altering experiences ("absorption"), a trait related to hypnotic susceptibility. Journal of Abnormal Psychology, 83, 268-277. https://doi.org/10.1037/h0036681

Wittmann, M. (2015). Modulations of the experience of self and time. Consciousness and Cognition, 38, 172-181. https://doi.org/10.1016/j.concog.2015.06.008 
Yeterian, J. D., Bursik, K., \& Kelly, J. F. (2018). "God put weed here for us to smoke": A mixedmethods study of religion and spirituality among adolescents with cannabis use disorders. Substance Abuse, 39(4), 484-492. https://doi.org/10.1080/08897077.2018.1449168 